\title{
Eradicant and curative treatments of hexanal against peach brown rot
}

\author{
Juliana Silveira Baggio, Silvia de Afonseca Lourenço, Lilian Amorim*
}

University of São Paulo/ESALQ - Dept. of Plant Pathology and Nematology, Av. Pádua Dias 11, C.P. 9 - 13418-900 Piracicaba, SP - Brazil.

${ }^{*}$ Corresponding author <lilian.amorim@usp.br>

Edited by: Cláudio Marcelo Gonçalves de Oliveira

Received April 29, 2013

Accepted August 09, 2013

\begin{abstract}
Brown rot, caused by Monilinia spp., is one of the most important peach (Prunus persica (L.) Batsch) diseases and the main cause of postharvest losses. Currently, alternative methods for postharvest disease control, such as the use of volatiles, are under investigation. The objective of this study was to determine the effects of hexanal on the in vitro development of Monilinia fructicola and $M$. laxa and on monocyclic components of brown rot on peaches. To evaluate the effect on pathogen development in vitro, a single dose of $215 \mu \mathrm{L}$ of liquid hexanal was placed on glass jars in closed plastic containers $(4.3 \mathrm{~L})$ at the moment of fungi transfer, 24 or $48 \mathrm{~h}$ after transferring to Petri dishes. After hexanal application, the Petri dishes were kept inside the containers that were closed for $24 \mathrm{~h}$ at $20^{\circ} \mathrm{C}$. Mycelial growth was measured seven days after hexanal removal. For in vivo assays, inoculated fruits were kept in closed plastic containers, and hexanal was applied at the moment of fruit inoculation or 24 hours thereafter. The monocyclic components infection frequency, expressed as brown rot incidence, lesion diameter and lesion sporulation, were assessed daily for seven days. Overall, hexanal was more effective in inhibiting mycelial growth when applied at the moment of pathogen transfer. Hexanal did not prevent pathogen infection, but reduced lesion diameter and completely inhibited spore production on the fruit for both treatments. Hexanal provides a promising alternative for chemical control and can be used in postharvest handling systems.
\end{abstract}

\section{Introduction}

Brown rot, caused by Monilinia fructicola (G. Winter) Honey, M. laxa (Aderhold \& Ruhland) Honey, and $M$. fructigena Honey, is one of the most important peach (Prunus persica (L.) Batsch) diseases due to the high crop losses it causes around the world (Ogawa et al., 1995). In Brazil, M. fructicola is the most prevalent species (May de Mio et al., 2011), although $M$. laxa has been recently reported in the Southeastern region (Souza et al., 2008). The disease starts in the fields, however, in most cases the symptoms are expressed only at the ripe fruit stage (quiescent disease) (Ogawa et al., 1995). The pathogen penetrates fruits mainly through wounds, caused by insects in the field or by harvest and postharvest handling (Neri et al., 2007).

In conventional and integrated production systems, brown rot is controlled by preventive applications of fungicides during blooming and pre-harvest. Postharvest fungicide use is allowed only in few countries, and restrictions to its use are increasing (Neri et al., 2007). This fact has stimulated research on alternative methods for controlling fruit diseases, such as through the use of plant volatile compounds (Cowan, 1999; Neri et al., 2006; Neri et al., 2007), or essential oils (Isman, 2000; Tripathi and Dubey, 2004). Plant volatile compounds can inhibit microorganism development (Caccioni et al., 1995) and sporulation (Fries, 1973). Such products are associated with plant defence mechanisms and could be extracted and applied to other harvested perishables. The aldehydes trans-2-hexenal, citral, and hexanal are examples of volatile compounds (Neri et al., 2007).

Hexanal is produced by the oxidative degradation of fatty acids, and contributes to the "green" taste of many fruit and vegetables species (Croteau, 1978), including peaches (Aubert and Milhet, 2007). A commercial product with hexanal as active ingredient is available and has been approved as a food additive by the US Food and Drug Administration (FDA) (Song et al., 1996). Botanical fungicides have lower human risks and animal toxicities, and cause less environmental pollution and their research and development costs are lower than synthetic fungicides (Tripathi and Dubey, 2004). The purpose of the present research was to determine the effectiveness of hexanal on the inhibition of the in vitro development of $M$. fructicola and $M$. laxa and on the control of brown rot development on peaches inoculated with the same pathogens.

\section{Materials and Methods}

Effects of hexanal on mycelial growth and sporulation of $M$. fructicola and M. laxa

Monilinia fructicola and M. laxa, isolated from Brazilian peach orchards, were cultured on PotatoDextrose-Agar (PDA) and kept at $20{ }^{\circ} \mathrm{C}$ in the dark (Biggs and Northover, 1988). From seven-day-old colonies, $0.5-\mathrm{cm}$-mycelial plugs of the pathogens were transferred to Petri dishes containing Potato-DextroseAgar (PDA). These dishes were kept uncovered inside a closed plastic container with a glass jar where 215 $\mu \mathrm{L}$ of liquid hexanal (purity $=98 \%$ ) were added. The plastic containers were made from polypropylene (bottom and cover) (285 mm long, $214 \mathrm{~mm}$ wide and 104 $\mathrm{mm}$ high $(4.3 \mathrm{~L}), 6.06 \mathrm{~mm}$ thick, and $1.92 \mathrm{~mm}$ in cover thickness). The container cover was tightly fixed. The hexanal concentration at application was $50 \mu \mathrm{L} \mathrm{L}^{-1}$ of the container. 
Three uncovered Petri dishes of each pathogen were used inside each container, and three containers, maintained inside growth chambers at $20{ }^{\circ} \mathrm{C}$, were used per treatment. Treatments were hexanal application as a single dose at the moment of fungi transfer $\left(\mathrm{H}_{0}\right), 24\left(\mathrm{H}_{24}\right)$ or $48 \mathrm{~h}\left(\mathrm{H}_{48}\right)$ after transferring. The product was kept in the closed containers for $24 \mathrm{~h}$, and after this period, the containers were opened. The concentration of the volatile inside the containers at the end of the treatment and the volatile absorption by PDA were not measured. $\mathrm{H}_{0}$ corresponded to an eradicative treatment, and $\mathrm{H}_{24}$ and $\mathrm{H}_{48}$ to curative treatments. Control treatments did not receive the volatile compound and were used for each period of hexanal application.

Colony diameters were measured along two axes perpendicular to each other seven days after opening the containers and the average of the two diameters was recorded as the colony diameter. Mycelial growth reduction of the fungi was calculated according to the formula: (1 - $\mathrm{CD}_{\mathrm{H}} / \mathrm{CD}_{\mathrm{C}} \mathrm{l} \times 100$, in which $\mathrm{CD}_{\mathrm{H}}$ is the colony diameter in the hexanal treatment and $\mathrm{CD}_{\mathrm{C}}$ is the colony diameter in the control treatment. The results were expressed in percentage. The experiment was repeated once.

Fungi spore production in hexanal and control treatments was quantified seven days after opening the containers for each treatment. From each Petri dish, a mycelial plug $(0.5 \mathrm{~cm}$ in diameter) was removed approximately $2 \mathrm{~cm}$ from the centre of the dish. This disc was placed in a test tube of sterile distilled water $(10 \mathrm{~mL})$, $10 \mu \mathrm{L}$ of Tween 20 and $30 \mu \mathrm{L}$ of lactoglycerol to prevent spore germination. From these suspensions, an aliquot of $0.2 \mathrm{~mL}$ was transferred to a haemocytometer to count the spores. The data were transformed to spores per $\mathrm{cm}^{2}$ of the colony.

Effects of hexanal on brown rot incidence and lesion development

The same isolates of $M$. fructicola and $M$. laxa used in the in vitro experiment were inoculated on peaches and kept in growth chambers at $20{ }^{\circ} \mathrm{C}$ for seven days to produce the inoculum for the in vivo experiments. Spore suspensions were prepared by adding $10 \mathrm{~mL}$ of sterile distilled water on the fruit with the pathogen. Mycelium and spores were scraped with a brush and then filtered by a double layer of cheesecloth. Spore concentrations were determined with a haemocytometer and adjusted to $10^{5}$ spores $\mathrm{mL}^{-1}$.

Peaches were purchased from the São Paulo wholesale market, and the maturity stage of the fruits was determined by physical-chemical analyses. The peaches presented a firmness of $17.9 \mathrm{~N}$ on average and soluble solids content of $8.85^{\circ}$ Brix. Only visibly undamaged and disease-free fruits were used in the experiments. The peaches were surface disinfested by immersing them in a sodium hypochlorite $0.5 \%$ solution for two minutes and then leaving them to dry at room temperature.

Fruits were wounded on the equator region with a sterile nail ( $3 \mathrm{~mm}$ deep and $1 \mathrm{~mm}$ wide). An aliquot of 30 $\mu \mathrm{L}$ of the pathogen spore suspension was applied over the wound. Eight peaches were placed inside the same type of containers used in the previous experiments with wet cottons (to provide a moist chamber) and a glass jar to which $215 \mu \mathrm{L}$ of liquid hexanal were added. The volatile was applied at the moment of fruit inoculation (eradicative treatment) or $24 \mathrm{~h}$ after inoculation (curative treatment). The containers were immediately closed and kept at $20^{\circ} \mathrm{C}$ inside a growth chamber. Hexanal was kept for $24 \mathrm{~h}$ in each container, which was kept opened after this period. The hexanal concentration inside the containers at the end of the treatment and the volatile absorption by the fruits were not measured. Control treatments did not receive the volatile. Three containers were used per treatment (replications). Three experiments with the peach cultivar 'Chiripá' were carried out.

The number of infected fruits (disease incidence) and lesion diameters were assessed daily for seven days. Fruit with a softening aspect on the region of the pathogen inoculation were considered diseased. Lesion diameter was measured in two perpendicular directions and the average of the two measurements was recorded as lesion diameter. Spore production was quantified at the end of the second and third experiments. From each fruit, a $0.25 \mathrm{~cm}^{2}$ square piece was removed approximately one centimetre from the wound. This piece was placed in a test tube with sterile and distilled water (3 $\mathrm{mL}), 10 \mu \mathrm{L}$ of Tween 20 , and $30 \mu \mathrm{L}$ of lactoglycerol to prevent spore germination. From these suspensions, an aliquot of $0.2 \mathrm{~mL}$ was transferred to a haemocytometer to count the spores. Data were transformed to spores per $\mathrm{cm}^{2}$ of colony.

\section{Data analysis}

The means of mycelial growth reduction for $M$. fructicola and $M$. laxa treated with hexanal, expressed in percentage in relation to the control treatments, were compared by Tukey's test $(p<0.05)$. A linear model $(y=a+b x$, where $y$ is the lesion diameter, $a$ and $b$ are regression coefficients, and $\mathrm{x}$ is time) was fitted to the lesion diameter development over time. The angular coefficient of each regression was compared to each other by the t-test.

\section{Results}

Effects of hexanal on mycelial growth and sporulation of $M$. fructicola and M. laxa

All hexanal treatments reduced the mycelial growth of $M$. fructicola and $M$. laxa. The hexanal application at the moment of fungi transfer $\left(\mathrm{H}_{0}\right)$ caused a reduction of $100 \%$ and $83 \%$ for $M$. fructicola and M. laxa, respectively, in relation to the control treatment (Figure 1). Hexanal application at 24 and $48 \mathrm{~h}$ after fungi transfer reduced mycelial growth by $95 \%$ and $76 \%$ for $M$. fructicola and by $71 \%$ and $65 \%$ for $M$. laxa, respectively. All hexanal treatments completely inhibited spore production after seven days of the volatile removal, while in 
control treatments, spore production ranged from $3.45 \mathrm{x}$ $10^{4}$ to $7.08 \times 10^{4}$ spores per $\mathrm{cm}^{2}$ of colony (Figure 1 ).

\section{Effects of hexanal on brown rot incidence and le- sion development}

Monilinia fructicola and $M$. laxa were able to infect peaches regardless of the treatment. Final disease incidence was higher than $80 \%$ for all treatments. However, lesions were reduced in hexanal treatments when compared to the control treatments $(p<0.05)$. Hexanal used as a single dose on eradicative and curative treatments showed significant reduction in the lesion development (Figures 2 and 3) and completely inhibited spore production over the fruit (Figure 2). The curative treatment $\left(\mathrm{H}_{24}\right)$ showed higher reduction in the disease development than the eradicant treatment $\left(\mathrm{H}_{0}\right)$ for both pathogens in all experiments, demonstrating that hexanal will have an effect on the disease development even after pathogen penetration into fruit. The lesion development rate $(b)$, represented by the slope of the linear model fitted to the lesion diameter, was slower in curative treatments than in eradicative treatments (Table 1). The same rate also was slower for peaches inoculated with $M$. laxa than with $M$. fructicola (Table 1). Besides, at the last day of evaluation, lesion diameter on fruit inoculated with $M$. laxa was smaller than on fruit inoculated with $M$. fructicola (Figure 3).

\section{Discussion}

Hexanal, applied as a single dose at the moment of fungi transfer and kept for $24 \mathrm{~h}$, had a completely growth inhibition of $M$. fructicola and a mycelial growth inhibition of M. Laxa, greater than $80 \%$. Similar results were observed when benzaldehyde, ethyl benzoate and methyl salicylate were tested against $M$. fructicola and

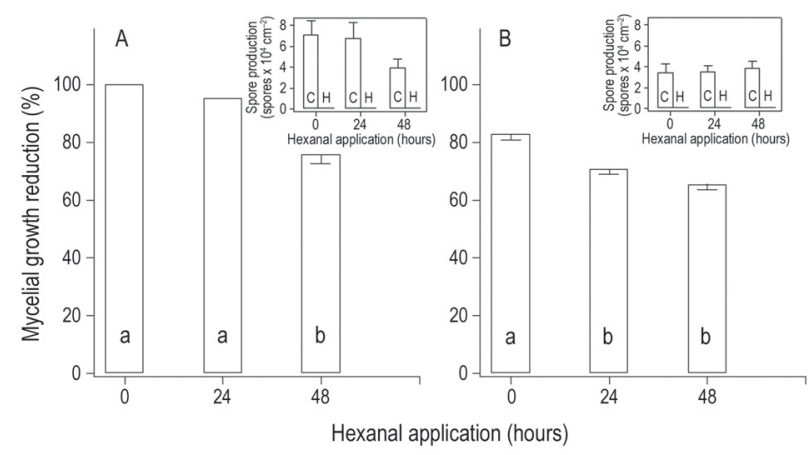

Figure 1 - Mycelial growth reduction and spore production (spores $\times 10^{4} \mathrm{~cm}^{-2}$ ) for Monilinia fructicola (A) and M. laxa (B). Treatments correspond to hexanal application at the moment of mycelial transfer (0), 24 hours (24) and 48 hours (48) after transfer. Spore production in control treatments $(\mathrm{C})$ and hexanal treatments $(\mathrm{H})$ are represented for each period of hexanal application. Columns with different letters differed (Tukey's test, $p<0.05$ ). Values represent means of two experiments.
Botrytis cinerea, although these compounds were kept in closed containers for a longer period (two weeks) (Wilson et al., 1987). On the other hand, a similar dose of hexanal used against an European strain of M. laxa 157.2 $\mu \mathrm{L} \mathrm{L}^{-1}$ ) inhibited only $50 \%$ of its mycelial growth (Neri et al., 2007). Fungicidal activity against Penicillium expansum was only achieved when hexanal was applied at the rate $98.4 \mu \mathrm{L} \mathrm{L}^{-1}$ (Neri et al., 2006). Mycelial growth of Sclerotinia sclerotiorum, Colletotrichum gloeosporioides and Alternaria alternata was almost completely inhibited after a 12-h exposure to $900 \mu \mathrm{L} \mathrm{L}^{-1}$ hexanal vapor (Song et al., 2007), while in our study, $215 \mu \mathrm{L}$ of hexanal applied as a single dose inside the containers $(4.3 \mathrm{~L})$ at the moment of fungi transfer had the same effect on $M$. fructicola.
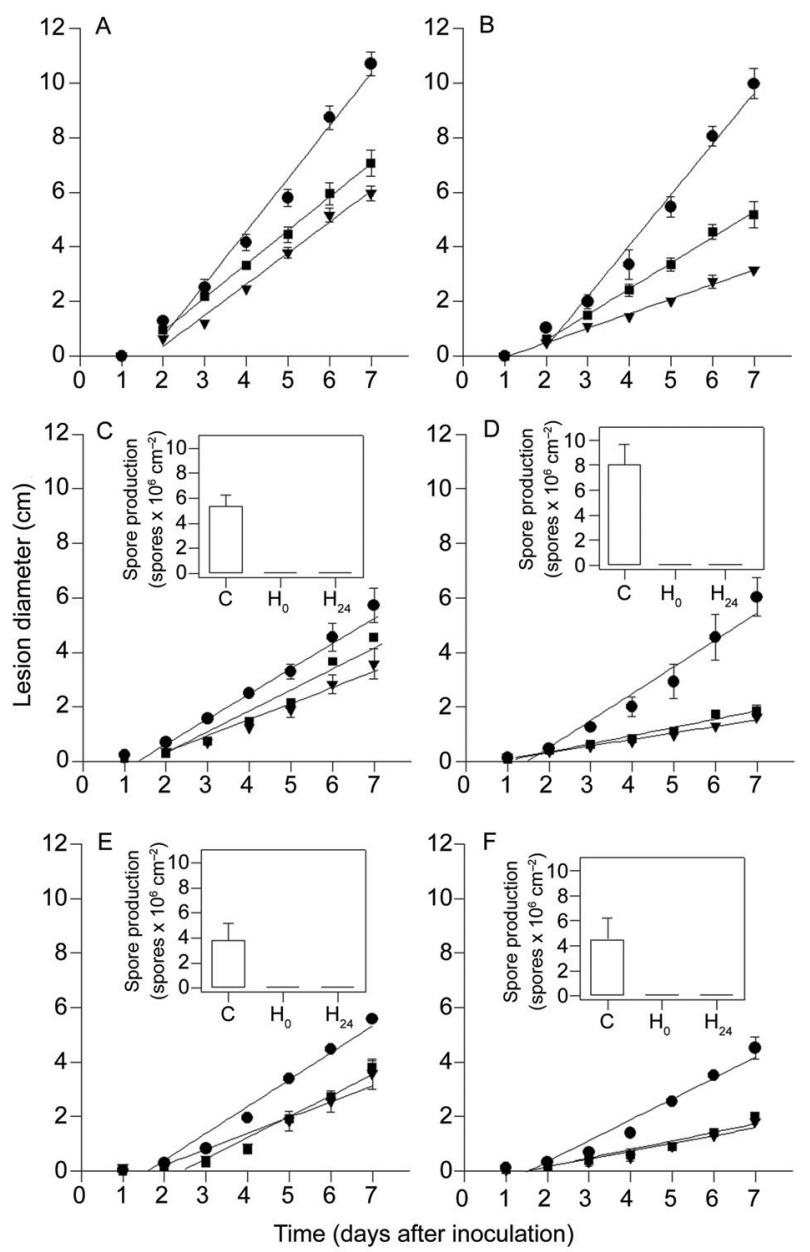

Figure 2 - Lesion diameter in the first $(A, B)$, second $(C, D)$ and third $(E, F)$ experiments and spore production (spores $\times 10^{6} \mathrm{~cm}^{-2}$ ) in the second $(C, D)$ and third $(E, F)$ experiments of Monilinia fructicola $(A, C, E)$ and $M$. laxa (B, D, F) on peaches of cv. 'Chiripá'. Circles correspond to control treatment, squares represent the eradicative treatment $\left(\mathrm{H}_{0}\right)$ and triangles represent the curative treatment $\left(\mathrm{H}_{24}\right)$. Lines represent fitted curves to lesion development by the linear model. Bars represent control $(\mathrm{C})$ and hexanal treatments $\left(\mathrm{H}_{0}\right.$ and $\mathrm{H}_{24}$ ) and there was no spore production in hexanal treatments. 


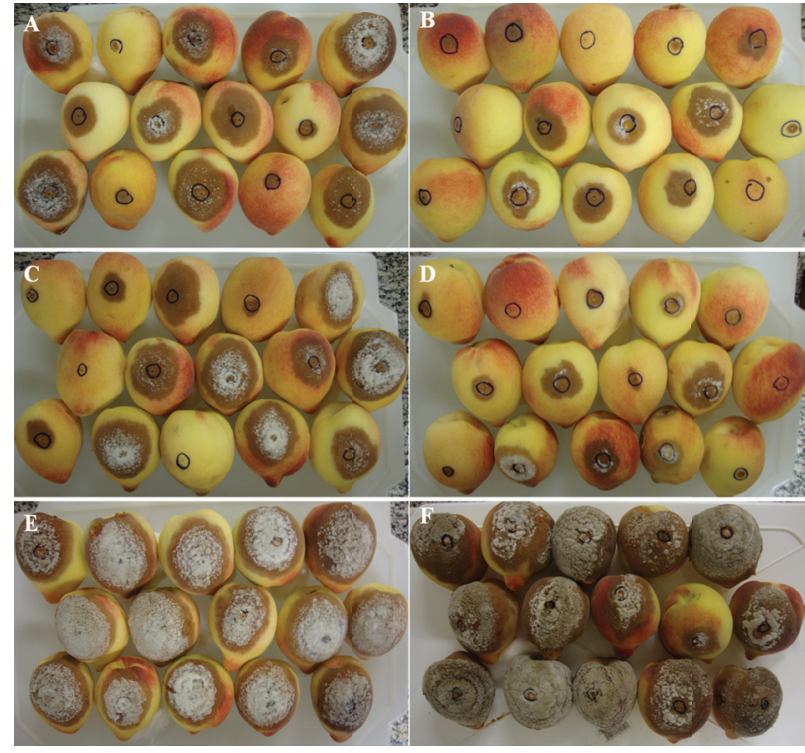

Figure 3 - Peaches inoculated with Monilinia fructicola (A, C, E) and $M$. laxa $(B, D, F)$, and treated with hexanal at the moment of inoculation, $H_{0}(A, B)$, at $24 \mathrm{~h}$ after this process, $\mathrm{H}_{24}(C, D)$, and not treated (control) (E, F).

A fungicidal effect for $M$. fructicola similar to that found for C. acutatum was also observed. This pathogen, however, was kept for seven days in closed containers and exposed to lower doses of hexanal (Almenar et al., 2007). Nevertheless, hexanal had a fungistatic effect against $M$. laxa, as the pathogen growth was observed even after $24 \mathrm{~h}$ of volatile exposure, similar to the results found for $A$. alternata and $B$. cinerea (Almenar et al., 2007) and P. expansum when treated with $73.8 \mu \mathrm{L} \mathrm{L}^{-1}$ after a 7-day exposure (Neri et al., 2006).

Hexanal did not completely suppress the development of peach brown rot, but it had an antifungal activity against Monilinia spp. by reducing the increase of lesion size and completely inhibiting sporulation $(p$ $<0.05$ ). Our results are promising and useful because Monilinia spp. control in peaches was achieved using a single application of hexanal for short period of fruit exposure to the volatile.

Although many researchers reported higher levels of fruit rot control, greater efficiency was reached when higher doses, longer exposure periods and continuous application of hexanal were used (Caccioni et al., 1995; Fan et al., 2006; Song et al., 2007; Utto et al., 2007). For example, tomato (Lycopersicon esculentum Mill) grey mould was almost completely controlled when hexanal was continuously applied for seven days on inoculated fruit (Utto et al., 2007). Similarly, lesion size of blue mould caused by $P$. expansum was reduced when apples were exposed to hexanal for two days (Fan et al., 2006). Caccioni et al. (1995) reported that a single dose of hexanal applied at $150 \mu \mathrm{L} \mathrm{L}^{-1}$ on nectarines (Prunus persica (L.) Batsch) completely inhibited brown rot development
Table 1 - Slope (b) and $\mathrm{R}^{2}$ of linear models fitted to the lesion diameter development over time for Monilinia fructicola and M. laxa.

\begin{tabular}{|c|c|c|c|c|c|c|}
\hline & \multicolumn{6}{|c|}{ M. fructicola } \\
\hline & \multicolumn{2}{|c|}{ Experiment 1} & \multicolumn{2}{|c|}{ Experiment 2} & \multicolumn{2}{|c|}{ Experiment 3} \\
\hline & $b^{*}$ & $\mathrm{R}^{2}$ & $b^{*}$ & $\mathrm{R}^{2}$ & $b^{*}$ & $\mathrm{R}^{2}$ \\
\hline Control & $1.93 a$ & 0.98 & $0.92 \mathrm{a}$ & 0.99 & $0.98 a$ & 0.97 \\
\hline $\mathrm{H}_{0}$ & $1.23 \mathrm{~b}$ & 0.99 & $0.77 b$ & 0.94 & $0.77 \mathrm{~b}$ & 0.95 \\
\hline \multirow[t]{4}{*}{$\underline{\mathrm{H}_{24}}$} & $1.14 \mathrm{c}$ & 0.99 & $0.59 c$ & 0.95 & $0.58 c$ & 0.92 \\
\hline & \multicolumn{6}{|c|}{ M. laxa } \\
\hline & \multicolumn{2}{|c|}{ Experiment 1} & \multicolumn{2}{|c|}{ Experiment 2} & \multicolumn{2}{|c|}{ Experiment 3} \\
\hline & $b^{*}$ & $\mathrm{R}^{2}$ & $b^{*}$ & $\mathrm{R}^{2}$ & $b^{*}$ & $\mathrm{R}^{2}$ \\
\hline Control & $1.86 \mathrm{a}$ & 0.98 & $0.98 \mathrm{a}$ & 0.95 & $0.76 \mathrm{a}$ & 0.95 \\
\hline $\mathrm{H}_{0}$ & $0.94 \mathrm{~b}$ & 0.99 & $0.30 \mathrm{~b}$ & 0.98 & $0.31 \mathrm{~b}$ & 0.93 \\
\hline $\mathrm{H}_{24}$ & $0.54 \mathrm{c}$ & 0.99 & $0.24 \mathrm{c}$ & 0.98 & $0.28 c$ & 0.93 \\
\hline
\end{tabular}

${ }^{*}$ Numbers followed by different letters indicate differences according to t-test.

$48 \mathrm{~h}$ after the fruit was inoculated with M. laxa. Moreover, the use of the volatile at the rate of $900 \mu \mathrm{L} \mathrm{L}^{-1}$ in a flow system markedly reduced lesion development on peaches inoculated with $M$. fructicola and raspberries infected by B. cinerea (Song et al., 2007).

The curative treatment with hexanal applied after $24 \mathrm{~h}$ on peaches inoculated with Monilinia spp. showed a higher efficiency of disease control than the eradicative treatment. This is interesting because of the quiescent behavior of this pathogen. Similar results were observed when trans-2-hexenal vapor $\left(12.5 \mu \mathrm{L} \mathrm{L}^{-1}\right)$ was applied on pears inoculated with $P$. expansum (Neri et al., 2006). While hexanal seems not to cause phytotoxicity in peaches, it is suggested that trans-2-hexenal fumigation promotes phytotoxicity (Neri et al., 2007).

In the literature reports can be found on spore viability when fungi are treated with volatiles (Fan et al., 2006; Neri et al., 2006; Song et al., 2007; Wilson et al., 1987). However, there are no studies on the effect of these products on fungi spore production. In our research, hexanal completely inhibited $M$. fructicola and $M$. laxa sporulation in vitro and on peaches, showing that fungi dispersal to other fruits can be avoided.

In Brazil refrigeration techniques during fruit transportation, storage and commercialization are not often used. Therefore, the use of hexanal for short periods at low concentration and as a single dose rather than a flow system, is relevant. This technique is highly recommended for use in the postharvest system in Brazil, as it is inexpensive and easy to handle.

\section{Conclusions}

Hexanal at the rate of $50 \mu \mathrm{L} \mathrm{L}^{-1}$ at the moment of application, used as a single dose had a direct negative effect on the mycelial growth and sporulation of $M$. fructicola and $M$. laxa in vitro. In addition, the volatile reduced the severity of the brown rot and completely inhibited fungi reproduction on peaches. The use of volatile compounds, such as hexanal, to control postharvest 
diseases provides a promising alternative to chemical fungicides and postharvest handling at storage systems.

\section{Acknowledgements}

This work was supported by contract no. 2009/53328-8 from the Fundação de Amparo à Pesquisa do Estado de São Paulo (FAPESP).

\section{References}

Almenar, E.; Auras, R.; Rubino, M.; Harte, B. 2007. A new technique to prevent the main post harvest diseases in berries during storage: inclusion complexes -cyclodextrin-hexanal. International Journal of Food Microbiology 118: 164-172.

Aubert, C.; Milhet, C. 2007. Distribution of the volatile compounds in the different parts of a white-fleshed peach (Prunus persica L. Batsch). Food Chemistry 102: 375-384.

Biggs, A.R.; Northover, J. 1988. Influence of temperature and wetness duration on infection of peach and sweet cherry fruits by Monilinia fructicola. Phytopathology 78: 1352-1356.

Caccioni, D.R.L.; Tonini, G.; Guizzardi, M. 1995. Antifungal activity of stone fruit aroma compounds against Monilinia laxa (Aderh. et Ruhl.) Honey and Rhizopus stolonifer (Ehrenb.): In vivo trials. Journal of Plant Diseases and Protection 102: 518525.

Cowan, M.M. 1999. Plant products as antimicrobial agents. Clinical Microbiolology Reviews 12: 564-582.

Croteau, R. 1978. Biogenesis of flavor components: volatile carbonyl compounds and monoterpenoids. p. 400-432. In: Hultin, H.O.; Milner, M., eds. Postharvest biology and biotechnology. Food and Nutrition Press, Westport, CT, USA.

Fan, L.; Song, J.; Beaudry, R.M.; Hildebrand, P.D. 2006. Effect of hexanal vapor on spore viability of Penicillium expansum, lesion development on whole apples and fruit volatile biosynthesis. Journal of Food Science 71: M105-M109.

Fries, N.F. 1973. Effects of volatile organic compounds on the growth and development of fungi. Transactions of the British Mycological Society 60: 1-21.
Isman, M. 2000. Plant essential oils for pest and disease management. Crop Protection 19: 603-608.

May de Mio, L.L.; Luo, T.; Michailides, T.J. 2011. Sensitivity of Monilinia fructicola from Brazil to tebuconazole, azoxystrobin, and thiophanate-methyl and implications for disease management. Plant Disease 95: 821-827.

Neri, F.; Mari, M.; Brigati, S. 2006. Control of Penicillium expansum by plant volatile compounds. Plant Pathology 55: 100-105.

Neri, F.; Mari, M.; Brigati, S.; Bertolini, P. 2007. Fungicidal activity of plant volatile compounds for controlling Monilinia laxa in stone fruit. Plant Disease 91: 30-35.

Ogawa, J.M.; Zehr, E.I.; Biggs, A.R. 1995. Brown Rot. p. 7-10. In: Ogawa, J.M.; Zehr, E.I.; Bird, G.W.; Ritchie, D.F.; Uriu, K.; Ueymoto, J.K., eds. Compendium of stone fruit diseases. American Phytopathological Society Press, Saint Paul, MN, USA.

Song, J.; Leepipattanawit, R.; Beaundry, R.M. 1996. Hexanal vapor is a natural, metabolizable fungicide: Inhibition of fungal activity and enhancement of aroma biosynthesis in apple slice. Journal of the American Society for Horticultural Science 121: 937-942.

Song, J.; Hildebrand, P.D.; Fan, L.; Forney, C.F.; Renderos, W.E.; Campbell-Palmer, L.; Doucette, C. 2007. Effect of hexanal vapor on the growth of postharvest pathogens and fruit decay. Journal of Food Science 72: 108-112.

Souza, D.C.; Fazza, A.C.; Camargo, L.A.; May de Mio, L.L.; Angeli, S.S.; Amorim, L. 2008. First report of Monilinia laxa causing brown rot on peaches in Brazil. Phytopathology 98: S148-S149.

Tripathi, P; Dubey, N.K. 2004. Exploitation of natural products as an alternative strategy to control postharvest fungal rotting of fruit and vegetables. Postharvest Biology and Technology 47: 434-437.

Utto, W.; Mawson, A.J.; Bronlund, J.E. 2007. Hexanal reduces infection of tomatoes by Botrytis cinerea whilst maintaining quality. Postharvest Biology and Technology 47: 434-437.

Wilson, C.H.; Franklin, J.D.; Otto, B.E. 1987. Fruit volatiles inhibitory to Monilinia fructicola and Botrytis cinerea. Plant Disease 71: 316-319. 